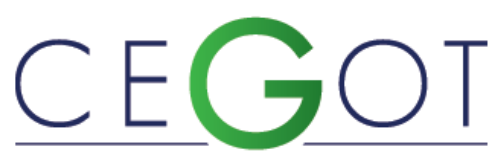

Centro de Estudos de Geografia e Ordenamento do Território
Vale, Raquel Matos Cardoso

Universidade Estadual de Feira de Santana

Departamento de Ciências Humanas e Filosofia 44036-900, Feira de Santana, Bahia, Brasil rmcvale@uefs.br

Perez-Alberti, Augusto

Universidade Santiago de Compostela

Departamento de Edafoloxîa e Química Agrícola. Facultade de Bioloxía. 15782, Santiago de Compostela, Espanha xepalber@gmail.com

\title{
USO DAS TERRAS E PROCESSOS DE DESERTIFICAÇÃO NA RPGA DOS RIOS MACURURÉ-
}

\author{
CURAÇÁ. BAHIA-BRASIL
}

LAND USE AND DESERTIFICATION PROCESSES IN THE RPGA MACURURÉ-CURAÇÁ RIVERS. BAHIA-BRASIL

Referência: Vale, Raquel Matos Cardoso; Perez-Alberti, Augusto (2021). USO DAS TERRAS E PROCESSOS DE DESERTIFICAÇÃO NA RPGA DOS RIOS MACURURÉ-CURAÇÁ. Revista de Geografia e Ordenamento do Território (GOT), no 22 (Dezembro). Centro de Estudos de Geografia e Ordenamento do Território, p. 05 - 27, dx.doi.org/10.17127/got/2021.22.001

\section{RESUMO}

Neste artigo são analisados os processos de desertificação na Região de Planejamento e Gestão das Águas dos Rios Macururé e Curaçá. O mapeamento do uso dos solos, por meio da fotointerpretação de imagens RapidEye, permitiu verificar que a Caatinga arbóreo-arbustiva antropizada, a Caatinga parque antropizada e a Agricultura ocupam mais da metade da região e apresentam perda de resiliência da vegetação. Estas são áreas de pastagens naturais que sustentam rebanhos extensivos cujo sobrepastejo gera danos, retroalimenta e amplia áreas de degradação ambiental. Por consequência, a capacidade de suporte das caatingas declina e os solos desnudos, expostos às intempéries e à erosão, atingem largas extensões. Nestas condições são observados células e núcleos de desertificação.

Palavras-chave: Semiárido; Resiliência; Desertificação; SIG.

\section{ABSTRACT}

In this article, are analyzed the processes of desertification in the Region of Planning and Management of the Waters of the Macururé and Curaçá Rivers. The mapping of land use, through photointerpretation of images RapidEye, allowed to verify that the anthropized Caatinga, the Caatinga anthropized park and Agriculture occupy more than half of the region and show decline of vegetation resilience. These are areas of natural pastures that support 
extensive herds whose overgrazing generates damage and expands areas of environmental degradation. As consequence, the caatingas support capacity declines and the bare soils, exposed to erosion, reach wide extensions. In these conditions, desertification cells and core are observed.

Keywords: Semi-arid; Resilience; Desertification; GIS.

\section{Introdução}

A Região de Planejamento e Gestão das Águas dos rios Macururé e Curaçá ${ }^{1}$ (RPGA-MC), localizada à margem direita do Rio São Francisco, no nordeste da Bahia (Figura 1), abrange $27.186,89 \mathrm{~km}^{2}$. As coordenadas UTM $319.799-9.058 .133$ e $609.716-8.865 .053$ enquadram esta região de águas, identificada como suscetível à desertificação no Plano Estadual de Combate à Desertificação e Mitigação dos Efeitos da Seca (BAHIA, 2014).

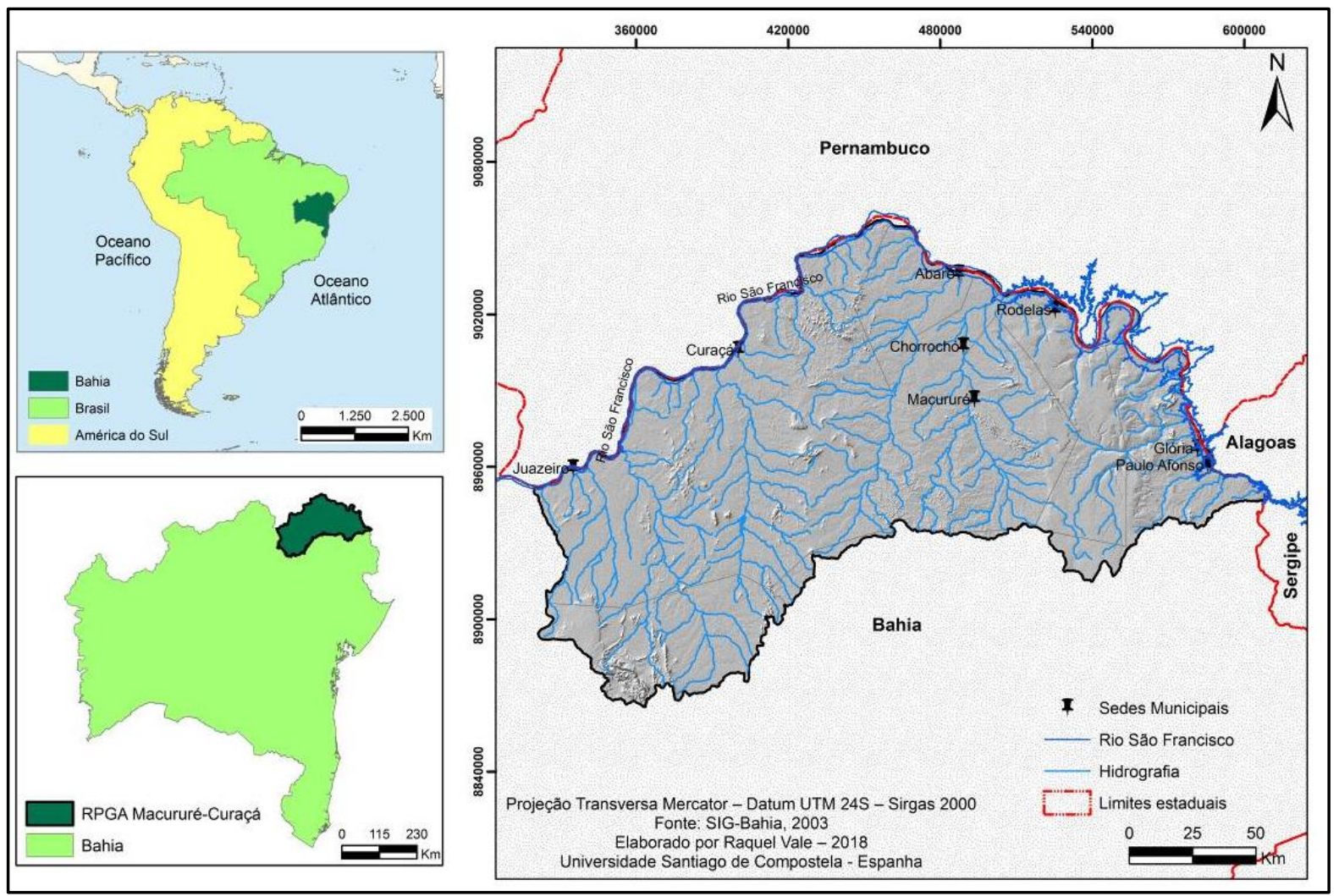

Figura 1 - Mapa de localização da RPGA-MC

\footnotetext{
${ }^{1}$ A poligonal da RPGA-MC abrange quatorze municípios; seis possuem área totalmente inserida na Região e oito apresentam-se inseridos em parte.
} 
Uma RPGA é a unidade espacial criada na Lei Federal 9.433/1997, ou Lei das Águas, para orientar a gestão pública e integrada das bacias hidrográficas brasileiras. Esta Lei instituiu a Política Nacional de Recursos Hídricos e criou o Sistema Nacional de Gerenciamento de Recursos Hídricos. No estado da Bahia, coube ao Instituto do Meio Ambiente e Recursos Hídricos/Inema a responsabilidade sobre a política estadual de recursos hídricos. Em 2005, o Ingá, hoje Inema, criou as RPGA's e, em 2009, o Conselho Estadual de Recursos Hídricos as redefiniu e instituiu as atuais 26 RPGA's - das quais, 08 possuem gestão compartilhada com os estados de Minas Gerais, Sergipe e Espírito Santo.

A desertificação é um processo que atinge grande parte das RPGA's do semiárido baiano e vem elaborando cenários profundamente negativos, tanto para os sistemas ambientais quanto para as populações locais. Tais aspectos, também presentes em todo semiárido brasileiro, levaram o Brasil a se tornar signatário da Convenção das Nações Unidas para o Combate à Desertificação e Mitigação dos Efeitos das Secas, em 1994 e, em 25 de junho de 1997 a ratificar a "Convenção Internacional de Combate à Desertificação nos Países Afetados por Seca Grave e/ou Desertificação, Particularmente na África". Ainda nesse mesmo ano instituiu a Política Nacional de Controle da Desertificação, aprovada pela Resolução no 238, de 22/12/97, do Conselho Nacional do Meio Ambiente. Desde então, têm sido tomadas medidas para controlar o processo e recuperar as áreas afetadas, em especial com a criação, em 2004, do Programa de Ação Nacional de Combate à Desertificação, PAN-Brasil, e em 2017, da Estratégia de Recuperação de Áreas Degradadas e Redução à Vulnerabilidade às Mudanças Climáticas, URAD.

A desertificação se caracteriza por apresentar profunda degradação ambiental, social e econômica, que decorre de uma série de fatores conhecidos e amplamente apresentados na literatura especializada. A exemplo, tem-se Geist e Lambin (2004) que identificaram em 132 casos descritos em 54 artigos e 28 jornais científicos, na Ásia, África, Austrália, Europa, Estados Unidos e América Latina, dois grupos de causas da desertificação: causas diretas relacionadas às atividades agrícolas, extensão da infraestrutura, extração de madeira e aumento da aridez; e causas ou forças motrizes subjacentes, derivadas dos fatores climáticos, econômicos, institucionais, políticas nacionais e crescimento populacional.

Em 2005 o Millennium Ecosystem Assessment estabeleceu o consenso em torno da indissociabilidade entre degradação do solo, mudanças climáticas e perda de biodiversidade. 
Perez-Marin et al. (2012) apontam que a desertificação na região semiárida brasileira geralmente decorre do desmatamento da caatinga para o plantio de pastos herbáceos ou culturas de ciclo curto, que não repõem os nutrientes dos solos e conduz à perda de fertilidade. A continuidade deste uso e manejo das terras secas tem resultado em erosão laminar com carreamento de solo de, em média, menos de $1 \mathrm{~cm} /$ ano. Porém, com o passar dos anos e a reincidência do processo há significativa redução da profundidade do solo, chegando à exposição da rocha. Estudos sobre o papel de erosão laminar na perda de solos (SAMPAIO et al., 2003) indicam que, apesar da baixa percepção por parte dos agricultores, existem evidências de que as práticas agrícolas inadequadas nos últimos 200 ou 300 anos esgotaram e rebaixaram os solos de forma irreversível em vários locais.

No que tange às evidências do processo de desertificação na Bahia, Lobão e Vale (2013) apresentaram para a Secretaria de Meio Ambiente da Bahia uma modelagem da suscetibilidade à desertificação para o estado, utilizando índice de vegetação, tipologia de solos e de vegetação, e uso dos solos, cujos resultados apontaram para a existência de $308.940 \mathrm{~km}^{2}$ de superfícies suscetíveis e fortemente suscetíveis ao processo, cerca de $80 \%$ de toda região semiárida baiana. O nordeste do estado, onde se localiza a RPGA-MC, está entre estas categorias de superfícies. Trata-se do sertão do submédio Rio São Francisco, onde se encontram os maiores índices de aridez e de incidência de secas, indicado no PAN-Brasil, 2004, como área suscetível a desertificação.

Para melhor compreender as causas deste processo no semiárido nordestino têm-se algumas questões centrais da história da formação agrária do território brasileiro, iniciada no século XVI, com a ocupação da costa atlântica. Este território foi palco de um processo de formação social e econômica que explica, em grande parte, a atual configuração agrária regional e, mesmo nacional. Seus reflexos estão registrados em múltiplos mosaicos de paisagens que guardam os matizes dessa história e o que existe hoje são as reminiscências construídas nesse passado.

Os episódios que melhor ilustram esta questão encontram-se entre os séculos XVI e XVII, quando o gado bovino, caprino e ovino, trazido de Portugal, ocupou as terras vale do Rio São Francisco. Os rebanhos eram criados em pastos extensivos abertos por queimadas e deixados "à lei da natureza" (BERNARDES, 1995); soltos, transitaram livres por toda parte, recortando e transformando as caatingas. Com o passar do tempo o Sertão foi se convertendo em um 
imenso pasto, como ainda o é - mais de $50 \%$ do rebanho de caprinos e ovinos do país estão inseridos no semiárido². Na RPGA-MC, somam um efetivo de mais de um milhão de cabeças (IBGE, 2013).

Por sua vez, as comunidades tradicionais, constituídas por indígenas, fundo e fecho de pasto, e quilombolas, habitam esses sertões há décadas e têm como atividades rurais preponderantes o pastoreio e a pequena agricultura. Estes povos dependem de relações de mútua solidariedade que contribuíram para preservar a cultura e os hábitos de um cotidiano diferenciado do que ocorria nas regiões mais dinâmicas da costa. De fato, é possível que tenha ocorrido uma relação bastante harmônica entre os hábitos e costumes destes povos, suas necessidades básicas, e a capacidade de sustentabilidade dos ambientes. Possibilitaram a conservação da diversidade e do endemismo das caatingas e, comparativamente aos espaços não tradicionais, evoluíram por meio de mecanismos retroalimentativos de alta resiliência. Deste modo, se observa a existência de dois cenários distintos no que tange ao uso das terras - um que se desenvolvia nas grandes propriedades, acompanhado por maior degradação ambiental e, outro de caráter mais conservacionista, praticado nas comunidades tradicionais. Na atualidade, a RPGA-MC se caracteriza por ser uma das regiões menos povoada e também menos desenvolvida da Bahia, onde as atividades rurais têm uma importância muito grande para a sobrevivência e permanência das populações locais, apesar dos rigores do clima e da insuficiente presença do Estado na atenção social e econômica aos munícipes. Em 2020, a densidade demográfica média foi de pouco mais de $10 \mathrm{hab} / \mathrm{km}^{2}$, conforme dados estimados pelo IBGE. Paulo Afonso, com 77 hab/ $\mathrm{km}^{2}$ e Juazeiro, $32 \mathrm{hab} / \mathrm{km}^{2}$, constituem exceção dentro do perfil regional; o primeiro por ser importante centro de geração de energia hidroelétrica e o segundo por ser o maior polo de fruticultura irrigada do nordeste baiano. As populações rurais são majoritárias, porém, já existe uma leve tendência de crescimento da população urbana.

Tais aspectos possibilitam compreender que as atividades rurais são essenciais para estas famílias - no último recenseamento agropecuário, realizado em 2006, a agricultura familiar predominava em $88 \%$ dos estabelecimentos rurais. Cabe ressaltar que, a extensão das terras, nesta categoria familiar, era de $43 \%$, dado que demonstra o quão concentrada é a estrutura

\footnotetext{
${ }^{2}$ Dados disponíveis no site da Embrapa Caprinos e Ovinos.
} 
fundiária - a agricultura nas grandes propriedades, geralmente de negócio, em que pese ocorrer em apenas $12 \%$ dos estabelecimentos, ocupa $57 \%$ das terras. Estes dados evidenciam estreita relação com as transformações que as paisagens vêm apresentando nesta região e que está dando lugar a feições degradadas e em desertificação.

Como se deu em todos os espaços semiáridos, a pecuária extensiva e a agricultura de subsistência carregam uma história de práticas agrícolas realizadas por meio do desmatamento e do uso insustentável dos recursos ambientais, à exceção, em parte, dos territórios tradicionais. Terras agrícolas exauridas são, em geral, abandonadas ou substituídas por pastos, e sua recomposição, ou recatingamento, raramente são observadas. Com isto tem-se uma degradação contínua, que acompanha a ocupação sócio-espacial, se agrava progressivamente e produz, não só a perda dos recursos, com a transformação e supressão dos ecossistemas naturais, mas também desestrutura as bases produtivas locais e regionais (COSTA NETO et al, 2011). Os reflexos sociais são muito negativos, sobretudo, pobreza, analfabetismo, desagregação das famílias, violência e êxodo. O estresse ambiental decorrente é potencializado, resultando em perda ecológica, falência das estruturas e das organizações sociais, e migração.

As formas de ocupação e uso das terras na RPGA-MC, o tamanho das transformações produzidas ao longo do tempo, os aspectos socioambientais que a categorizam como área suscetível à desertificação, estão articulados aos processos de desertificação observados em inúmeras áreas. Tais questões constituíram os critérios que orientaram para a escolha da RPGA-MC, como recorte espacial de estudo, com o objetivo de identificar as transformações das paisagens, derivadas das atividades humanas, e que têm conduzido para processos de desertificação.

\section{Metodologia}

A RPGA-MC é fortemente vulnerável aos episódios de seca, um fenômeno natural dos domínios semiáridos que fragiliza as dinâmicas de resiliência socioambiental. Os sucessivos ciclos de degradação dos recursos ambientais e pobreza que atingem tais áreas se retroalimentam e forçam a expansão das áreas produtivas, resultando em degradação física, química e biológica dos solos. Sampaio et al. (2008) apontam que a causa fundamental da 
desertificação é a forma como as atividades agrícolas são praticadas, as quais abrem caminho para a degradação. Mas ressaltam, que "as atividades agrícolas sempre resultam em alguma mudança das condições ambientais, fica para ser definido que níveis de mudança seriam aceitáveis" (p. 64), ou seja, o autor pressupõe, de modo assertivo, que a capacidade de resiliência ambiental é limitada.

Tendo em vista tais pressupostos foram definidos os procedimentos metodológicos para o estudo da desertificação na RPGA-MC - análise das principais referências da literatura especializada, levantamentos de campo, e mapeamento dos usos das terras. Existe uma diversidade de paisagens na região, desde as mais degradadas que acompanham as atividades humanas, até sítios de maior conservação localizados nas unidades de conservação, terras indígenas e zonas de difícil acesso. Entre um e outro ocorrem cenários diversos.

O mapeamento dos usos das terras foi ancorado na fotointerpretação das imagens do satélite RapidEye, tomadas em 2009/10. A ausência de uma série temporal de imagens com a resolução espacial deste satélite, 5 m, não possibilitou realizar uma análise da dinâmica dos processos de desertificação. Entretanto, permitiu observar indicadores de desertificação naquele momento, tais como, erosão hídrica, forte fragmentação da vegetação e ampla incidência de solos desnudos. Espera-se que na medida em que imagens mais recentes sejam produzidas seja possível acompanhar as mudanças temporais. Os levantamentos de campo foram feitos em várias etapas da pesquisa e na validação dos resultados.

O mapa produzido discriminou num primeiro nível hierárquico duas categorias de paisagens - as transformadas pelo uso e atividades humanas em oposição aos remanescentes de vegetação. A partir daí foram identificados os demais níveis representativos de cada categoria para, desta forma, reconhecer as diferentes tipologias e discutir sobre as áreas em processo de desertificação.

As imagens RapidEye apresentam bandas espectrais do visível até o infravermelho próximo e são apropriadas para visualizar e avaliar as superfícies antropizadas e também os fragmentos remanescentes de vegetação. Encontram-se disponibilizadas com ortorretificação, que corrigiu as deformações geométricas produzidas pela plataforma do sensor e, inicialmente, foram abertas no software ENVI 5.1, classic, onde imagens escuras foram filtradas para melhorar sua visualização. A composição colorida RGB-543, ideal para discriminar a 
vegetação, morfologia do relevo, rede de drenagem e espelhos d'água, foi adotada. Feito este processamento, foram salvas no formato do ArcGis. Oitenta cenas recobrem a região e, por esta razão, a fotointerpretação dos alvos foi feita separadamente sobre cada cena, para ao término, ser processado o mosaico e construído o mapa. Deste modo, foram evitadas dificuldades operacionais no processamento do software, em consequência do tamanho dos arquivos. O shape file da RPGA-MC foi adquirido na base de dados do Inema e utilizado para recortar a área de estudo e georreferenciar para coordenadas UTM, Datum SIRGAS 2000.

Tendo em vista que a resolução espacial de $5 \mathrm{~m}$ das imagens RapidEye permite excelente acuidade visual para discriminar os detalhes dos contornos dos alvos, estabeleceu-se a escala de 1:100.00 para confeccionar o mapa. A fotointerpretação e vetorização dos polígonos foram realizadas diretamente na tela do computador, aproveitando ao máximo a resolução espacial imagens. Concluída a vetorização das classes foi realizada topologia, transformação do arquivo raster para polígonos e calculadas suas respectivas áreas. Os layouts finais foram realizados no software ArcMap 10.3 do ArcGis.

Durante a vetorização escalas maiores foram utilizadas para aprimorar a interpretação dos alvos. Os critérios que subsidiaram a vetorização foram mapas pré-existentes do Sistema de Informação Georreferenciadas/Sig-Bahia, 2003; a coleção multitemporal de 2000 a 2016 do MapBiomas³; os manuais técnicos da Vegetação Brasileira (IBGE, 2012) e do Uso da Terra (IBGE, 2006), disponíveis na rede internet; mapas produzidos pela Secretaria de Meio Ambiente e Recursos Hídricos/Bahia, 2007; banco de dados georreferenciados de pontos amostrados em levantamentos de campo; presença de povoados, caminhos, trilhas, represas e aguadas; polígonos desmatados em meio à vegetação; textura e cor dos alvos.

O mapa resultante, Superfícies Transformadas e Remanescentes de Vegetação, discriminou as tipologias de usos existentes na RPGA-MC e os remanescentes, a partir das quais, foi possível estabelecer correlações com a degradação ambiental e processos de desertificação. Para tanto, foram definidos os conceitos-chave da discussão posta neste artigo, ancorados na análise da literatura consultada:

\footnotetext{
${ }^{3}$ O MapBiomas é um projeto de caráter interinstitucional, em rede, que utiliza processamento de dados em nuvem e classificadores automatizados desenvolvidos e operados a partir da plataforma Google Earth Engine. Tem por objetivo gerar séries históricas de mapas anuais de cobertura e uso da terra do Brasil. https://mapbiomas.org/
} 
1. Degradação ambiental - áreas que apresentam uma condição ambiental em desequilíbrio, resultante da exposição contínua a danos e impactos negativos derivados das atividades humanas.

2. Desertificação - áreas com forte presença das atividades humanas e predomínio da pecuária extensiva; acentuada e persistente transformação das paisagens e ausência, ou rarefação, de remanescentes de vegetação; erosão muito ativa, com presença de sulcos e ravinas; acentuada perda de solo observável pela exposição de raízes, lajedos e formas de assoreamento fluvial e pluvial. Constituem áreas com aguda degradação ambiental.

\section{A RPGA-MC no contexto do semiárido brasileiro}

A Resolução № 115 de 23/11/2017 redefiniu os limites do semiárido, o que ampliou o número de municípios baianos de 265 para $278-446.021$ km², 79\% do território. Segundo o Instituto Nacional do Semiárido, 2017, a região semiárida baiana possui 7,4 milhões de habitantes, metade da população estadual, e concentra mais de $50 \%$ da agropecuária. Este é, portanto, um estado com significativa parcela da população domiciliada no semiárido e dependente das atividades rurais, o que se traduz em um dos grandes desafios para a permanência destas populações nos seus locais de origem. A RPGA-MC exibe este mesmo caráter de ruralidade das atividades econômicas, porém, agravado, por se encontrar na porção de maior aridez do semiárido, o que limita enormemente as atividades produtivas rurais - as precipitações anuais predominam entre menos de 400 até $600 \mathrm{~mm}$.

As relações sociais e de produção, ainda arcaicas e com forte pressão sobre os recursos água e vegetação, tipifica e condiciona os usos das terras à escassez hídrica e às secas, o que conduz para uma grande fragilidade das atividades econômicas e do próprio sistema ecológico. Neste sentido, os aspectos climáticos e da cobertura vegetal, sistemicamente interdependentes, contribuem para compreender os mecanismos produtores da desertificação.

Dados analisados por (GIRÃO, 2012), para o conjunto do semiárido brasileiro, e que se aplicam a RPGA-MC, apontam que as médias pluviométricas anuais variam entre 300 e $800 \mathrm{~mm}$, com temperaturas e amplitudes térmicas médias anuais acima de $26^{\circ} \mathrm{C}$ e de $6^{\circ} \mathrm{C}$, respectivamente. 
A insolação é superior a 3.200 horas/ano e provoca acentuada evaporação (CONTI, 2005; FERREIRA e MELLO, 2005), resultando em ressecamento dos solos e rebaixamento dos níveis freáticos; períodos secos extremos podem se prolongar por mais de três anos consecutivos (RÊGO, 2012). Nestas condições, as práticas de manejo da pecuária e, principalmente, da agricultura tornam-se itinerantes, profundamente dependentes da ocorrência das chuvas e promotoras de danos, fatores que mais vulnerabilizam tais atividades e contribuem para desenvolver processos de desertificação. Apesar de avanços significativos, falta uma ação mais efetiva e continuada do poder público para criar e disponibilizar tecnologias que aumentem a oferta de água, sobretudo para dar sustentabilidade a agricultura e a pecuária.

Os mecanismos que explicam este implacável quadro climático e as secas persistentes são encontrados na circulação atmosférica sobre a América do Sul e sobre o nordeste do Brasil, e no comportamento dos oceanos Atlântico e Pacífico (NOBRE et al., 2006). Em contrapartida, eventos de La Niña, quando intensos, se traduzem por anos chuvosos; é cada vez mais provável que o El Niño Benguela seja um fenômeno que também controla o aumento das precipitações sobre o semiárido nordestino (REPOSSI e CANZIANI, 2009). Pesquisas para a região semiárida brasileira, realizadas por Jatobá et al. (2017) comungam das mesmas conclusões, o que ratifica, uma vez mais, que a convivência sustentável com o semiárido é a principal alternativa para as populações locais.

Para além destes fatores, os estudos conduzidos por Cavalcanti et al. (2002), apontam que as supressões da vegetação na Amazônia e no semiárido brasileiro comprometem as condições climáticas continentais. Haveria uma tendência para evolução de um novo estado de equilíbrio mais seco e maior escassez de água no Semiárido, que agravariam e expandiriam os processos de desertificação, sobretudo nas áreas de maior aridez. As repercussões têm sido avaliadas pelo Modelo de Circulação Geral da Atmosfera que revelaram que, em grande escala, o desmatamento na Amazônia e a desertificação no Semiárido podem levar à expansão de savanas na Amazônia e semidesertos no core seco do semiárido, por exemplo, onde se localiza a RPGA-MC, devido às transformações no ciclo hidrológico sobre as regiões (OYAMA e NOBRE, 2003). Segundo os autores, este novo estado de equilíbrio mais seco atingiria drasticamente a caatinga, por ser este, um bioma dos mais vulneráveis às mudanças climáticas. 
Nestas condições se encontra o bioma Caatinga, altamente adaptado, cuja extensão alcança $734.478 \mathrm{~km}^{2}, 75 \%$ da região nordeste, e que inclui "pelo menos uma centena de tipos de paisagens únicas, com rica biota e endemismos - a mais diversa que qualquer outro bioma no mundo, exposto às mesmas condições de clima e de solo" (BRASIL/MMA, 2003, p. 9). As caatingas são controladas pelos fatores topoclimáticos e edáficos e por isso apresentam-se com tanta diversidade. Na década de 1930 Philip von Luetzelburg (BERNARDES, 1999) distinguiu nada menos que 12 subtipos de caatingas. Sá, Riché e Fotius (BRASIL/MMA, 2003, p. 24) identificaram "vegetação hiperxerófila, nas áreas secas acentuadas, (34,3\%); vegetação hipoxerófila, nas menos secas, (43,2\%); ilhas úmidas (9,0\%); agreste e áreas de transição $(13,4 \%)^{\prime \prime}$.

Tais fatores climáticos impõem, aos fatores geoecológicos, grande diversidade de paisagens semiáridas (MELO, 1958 apud CONTI, 2005), onde o arranjo dos relevos são importantes para determinar estas diferenças. Para a região em estudo, as superfícies aplanadas São Franciscana, em altitudes entre 200 e $400 \mathrm{~m}$, controlam as tipologias de paisagens. Nestas, predominam solos rasos e pedregosos, lajedos e areões, acentuadas taxas de insolação e evaporação que concorrem para a existência de um sistema ambiental frágil, submetido a longos períodos de seca. A regeneração da caatinga é lenta, visto depender das chuvas, das formas de dispersão das sementes, de sementes sadias no solo e da rebrota de tocos e raízes.

Na RPGA-MC a Caatinga Parque hiperxerófila e a Arbórea-arbustiva hipoxerófila são predominantes e ocupam, de modo fragmentado, o vale do rio São Francisco, localmente subdividido nas superfícies aplainadas do Macururé, do Curaçá e do Tourão (VALE, 2018). Os sistemas fluviais endógenos, intermitentes, mas exorréicos, contribuem para a ausência de taxas de salinidade muito elevadas nos solos e lençóis subterrâneos, favorecendo, sob restrições, a ocupação das terras e a utilização dos recursos. Desta forma, a região é amplamente ocupada direta e/ou indiretamente, sobretudo pela caprino-ovinocultura, consorciada sazonalmente com a agricultura de subsistência e sequeiro.

\section{Superfícies Transformadas e Remanescentes de Vegetação}

Vale (2018), descreve que na região do submédio Rio São Francisco, onde se localiza a RPGAMC, ocorrem caatingas rústicas e pouco densas sobre as depressões; e arbóreas e mais densas 
nos tabuleiros, baixadas, terraços e beiras de rios, locais onde forma estratos florestados. Cáctus e bromélias, junto a outras herbáceas, constituem um complexo rupestre que viceja sobre lajedos, encostas e topos rochosos de inselbergues, serras e serrotes. Podem também ser observados atapetando o solo sob caatinga arbóreo-arbustiva, o que vem a indicar maior conservação biológica da vegetação.

Pastos extensivos e semiextensivos associados à retirada de lenha, desmatamentos e uso do fogo, recortaram e modificaram as caatingas na RPGA-MC. Abriram clareiras que se coalesceram sucessivamente dando origem a superfícies nuas e com forte incidência de radiação solar direta, onde processos de desertificação proliferam. As caraterísticas fitofisionômicas primordiais das caatingas encontram-se alteradas e parte de suas espécies não são observadas com a mesma frequência a não ser em sítios ou habitats geomorfológicos muito específicos (BRASIL/MMA, 2003).

Estes vários mosaicos puderam ser visualizados, interpretados e vetorizados sobre as imagens RapidEye, para elaborar o mapa das Superfícies Transformadas e Remanescentes de Vegetação (Figura 2). Os critérios adotados e apresentados na metodologia permitiram comparar as características dos polígonos e definir 17 tipologias:

1. Agricultura - agricultura sazonal de sequeiro ou irrigação.

2. Aluvião - superfícies assoreadas dentro e às margens dos canais fluviais.

3. Caatinga arbóreo-arbustiva - superfícies contínuas com Caatinga arbóreo-arbustiva.

4. Caatinga arbóreo-arbustiva aberta - coberturas descontínuas de Caatinga arbóreoarbustiva e que podem apresentar algum tipo de uso, porém de baixa frequência.

5. Caatinga arbóreo-arbustiva antropizada - superfícies com algum tipo de uso de alta frequência e que fragmenta de modo descontínuo Caatinga arbóreo-arbustiva.

6. Caatinga arbóreo-arbustiva e erosão - superfícies com algum tipo de uso que fragmenta de modo descontínuo Caatinga arbóreo-arbustiva, e com marcas de erosão.

7. Caatinga arbóreo-arbustiva densa - superfícies extensas e recobertas de modo contínuo por Caatinga arbóreo-arbustiva densa.

8. Caatinga arbóreo-arbustiva e sistemas erosivos - superfícies recobertas de modo contínuo por Caatinga arbóreo-arbustiva e que apresentam grande densidade de formas erosivas.

9. Caatinga arbóreo-arbustiva sobre afloramentos - superfícies rochosas de inselbergues ou serrotes recobertas por Caatinga arbóreo-arbustiva.

10. Caatinga arbóreo-arbustiva, erosão e solo exposto - superfícies com algum tipo de uso que fragmenta de modo descontínuo Caatinga arbóreo-arbustiva, erosão e solo exposto. 
11. Caatinga parque - superfícies recobertas de modo contínuo por Caatinga parque.

12. Caatinga parque antropizada - superfícies com algum tipo de uso de alta frequência e que fragmenta de modo descontínuo Caatinga parque.

13. Erosão hídrica - sistemas erosivos produzidos por escoamento fluvial e/ou pluvial.

14. Mineração - área de exploração mineral de alta frequência e de grande porte.

15. Rio São Francisco.

16. Solo exposto - superfícies com forte evidência de supressão da cobertura vegetal.

17. Área urbana - superfície ocupada por sedes municipais.

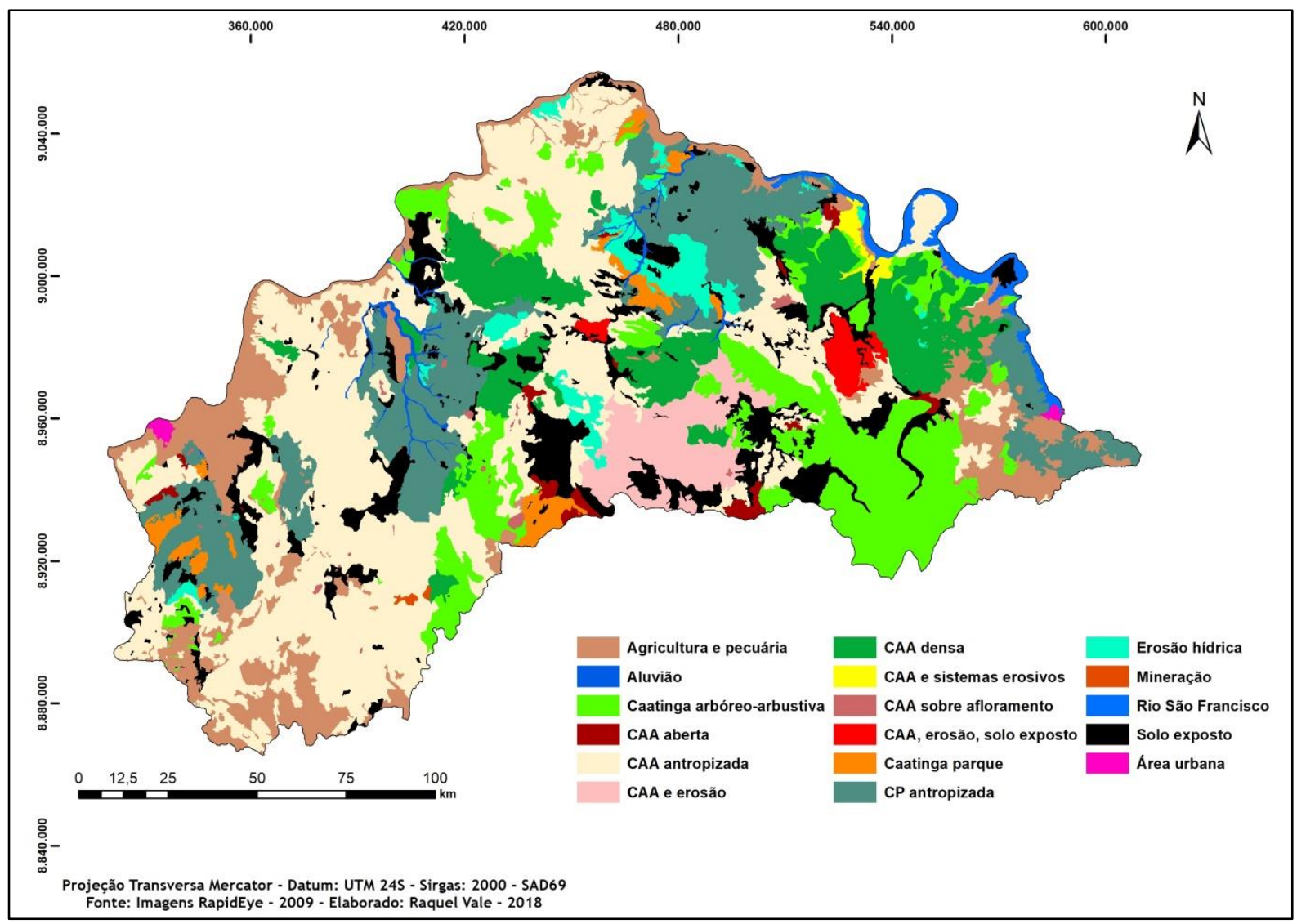

Figura 2 - Mapa das superfícies transformadas e remanescentes de vegetação

O maior espaçamento entre as plantas, a despeito de ser uma característica natural da caatinga, também foi interpretado, junto aos critérios citados, como indicador de antropização, visto que o predomínio de pastagens naturais e extensivas constrói uma densa rede de trilhas de pastejo e clareiras que vulnerabilizam o conjunto da vegetação. Nestas condições há maior exposição dos solos e, sobre os mais arenosos, pálidos e secos, a reflexão é acentuada e fortemente detectada pelo sensor dos satélites orbitais. Ressalta-se que, a 
rarefação na densidade da vegetação pode ser ainda mais severa ao se considerar o nível de generalização da escala de mapeamento. Estes parâmetros foram significativos para melhor compreender a composição da cobertura das terras, relativizar a interpretação dos alvos e identificar superfícies que tiveram sua fitofisionomia natural transformada.

Desta forma, foram discriminadas 12 classes na categoria transformada, $20.461,54 \mathrm{~km}^{2}$, ou $75,26 \%$ da região, e 05 na categoria remanescente, $6725,35 \mathrm{~km}^{2}$, ou 24,74\% (Gráfico 1), o que demonstra a intensidade com que as transformações vêm ocorrendo na região: $3 / 4$ das paisagens encontram-se afetadas por usos ou intervenções humanas decorrentes de uma longa história de exploração dos recursos ambientais e que estão relacionados com a desertificação. Merece destacar que, mesmo na categoria remanescente, foi possível identificar nos trabalhos de campo, indicadores de atividades humanas, porém menos frequentes e de menor dano à vegetação.

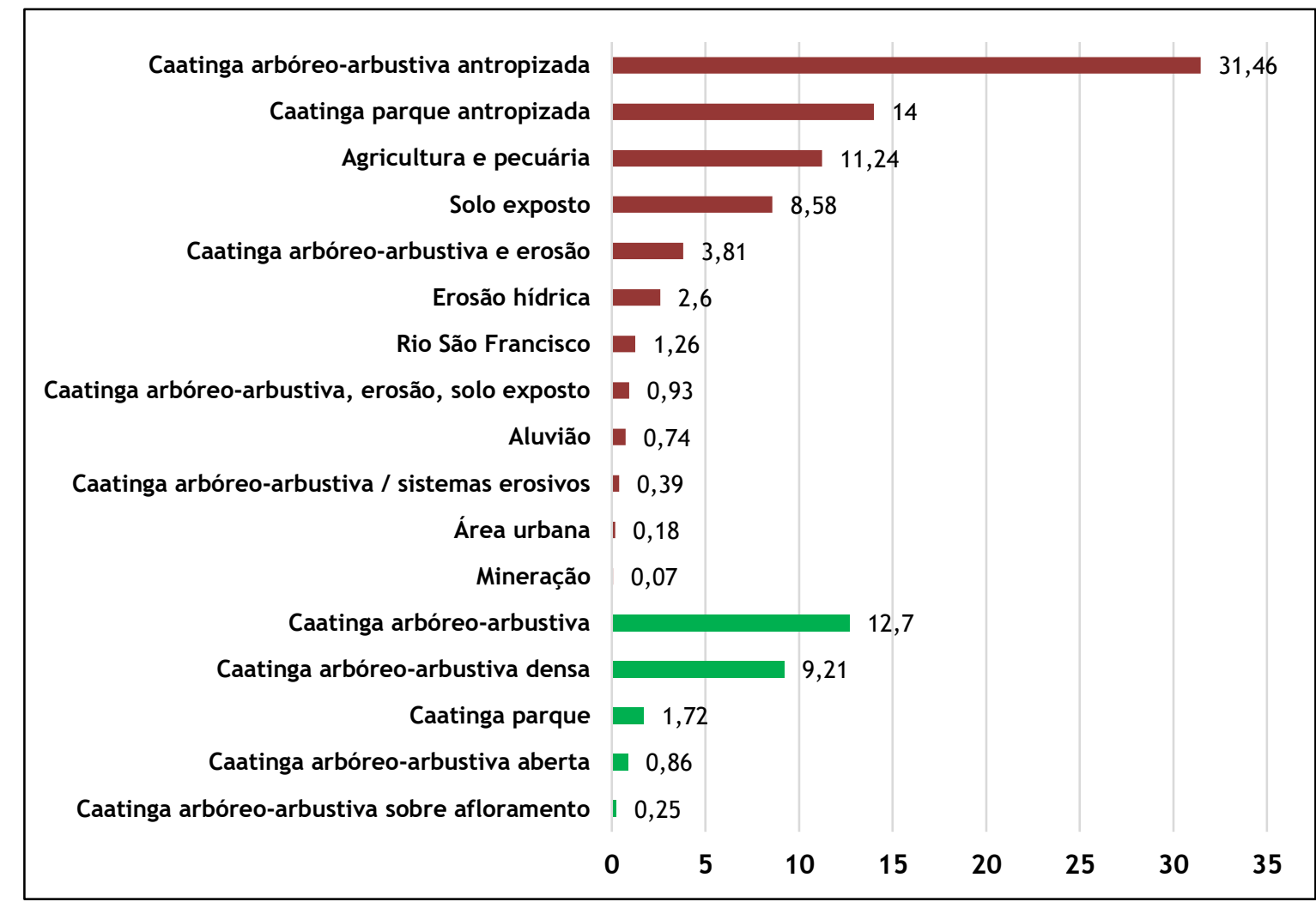

Gráfico 1. Composição das superfícies transformadas e remanescentes de vegetação (\%). 
A Caatinga arbóreo-arbustiva antropizada ocupa $31,46 \%$ da região e a Caatinga parque antropizada $14 \%$. Juntas somam $45,46 \%$ e representam a maior área contínua de caatinga ocupada e transformada, em que a pecuária de caprinos e ovinos, sobretudo, é a principal atividade produtiva.

As transformações observadas nestes subtipos de caatinga decorrem de inúmeros danos derivados da pecuária. Segundo dados do IBGE, 92\% do rebanho é formado por caprinos e ovinos - mais de 1 milhão de cabeças, em 2013. Encontram-se espalhados pela caatinga e ocupam enormes extensões de terras. São estes animais, principalmente, que têm provocado maior dano e ampliado áreas de pastejo extensivo.

Araújo Filho e Crispim (2002), com base em uma série de levantamentos iniciados na década de 1990, destacam a prevalência no semiárido, do pastoreio múltiplo ou combinado. Este é um tipo de manejo que permite que diferentes herbívoros compartilhem a mesma pastagem, na mesma estação. Quando se trata de pastejo múltiplo de bovinos, caprinos e ovinos em caatinga nativa, não ocorrem alterações significativas, desde que resguardadas as práticas de conservação. Porém, se houver sobrepastoreio, caprinos são muito danosos, pois anelam os troncos das plantas e destroem as plântulas.

Tais aspectos do sobrepastoreio, para além de reduzir a diversidade biológica da Caatinga, têm levado à degradação das pastagens e elevado o nível de estresse ambiental. A continuidade do dano rebaixa a vegetação arbóreo-arbustiva, tornando-a herbácea e de fácil acesso para caprinos e ovinos, o que empobrece ainda mais esse estrato e pode resultar no desaparecimento das gramíneas, cactáceas e bromeliáceas, e expor totalmente o solo. Resguarda-se, no entanto, que esta dinâmica flutua conforme as condições de chuva e, por conseguinte, das próprias condições fenológicas da vegetação. Herbáceas, arbustivas e arbóreas oferecem espécies bem aceitas ao paladar dos rebanhos, porém pouco nutritivas, tornando o sobrepastejo largamente itinerante. Por consequência, a riqueza da caatinga é comprometida; a fauna é afetada devido às modificações no tipo e na disponibilidade de alimentos e tende a buscar refúgios, tornando-se mais vulnerável.

De todo modo, os primitivos e imensos pastos naturais garantiram e ainda se constituem fonte de alimento e água para caprinos, ovinos e bovinos. Deixá-los soltos para pastejar é tradição, e explica, em parte, o atual contexto da pecuária extensiva regional, prática herdada 
que se constitui na base dos costumes rurais dos sertões semiáridos. Os recursos necessários para uma produção competitiva são insuficientes, ou inexistentes, o que tem preservado a tradição e mantido os animais em regime, sobretudo, extensivo, mesmo quando as propriedades são cercadas. Desta forma, observa-se que a sustentabilidade dos rebanhos e das populações rurais passou ao longo do tempo - séculos - a depender fortemente deste traço cultural dos sertanejos.

As pastagens naturais, cuja capacidade de suporte é menor do que dos pastos plantados são muito suscetíveis ao sobrepastoreio e ao pisoteio. Rapidamente, o estrato herbáceo se degrada e compromete as espécies forrageiras. Estas são as primeiras a desaparecer, o que vem a aumentar o número de herbáceas pioneiras indesejáveis que concorrem com outras espécies mais importantes. Assim, os rebanhos são forçados a deslocamentos maiores, para alcançar pastos com melhor oferta nutricional. Tamanho estresse tem tornado a caatinga cada vez mais empobrecida, decrescendo ainda mais sua capacidade de suporte e de resiliência frente ao manejo extensivo dos rebanhos.

A capacidade de suporte média para a região, calculada por Vale (2018), é de 2,8 ha de pastos para cada animal, por ano, abaixo do valor estimado como adequado para o semiárido brasileiro - 4,5 ha/cabeça/ano (ARAÚJO FILHO e CRISPIM, 2002). Trata-se de uma capacidade baixa, que deriva condições de sobrepastoreio e afeta fortemente a vegetação. Brotos e folhas jovens são fácil e rapidamente alcançados pelos animais, sobretudo, caprinos e ovinos, anelando os galhos e prejudicando o crescimento das plantas. Consequentemente, a vegetação torna-se sujeita a forte pressão ecológica que se propaga para os demais componentes da paisagem, principalmente, solos e recursos hídricos, afetando negativamente a produção e a produtividade das atividades rurais.

A segunda a maior área com transformações acentuadas corresponde à Agricultura, cuja extensão chega a 11,24\% da região, realizada, sobretudo ao longo das planícies e depressões que contornam os reservatórios das barragens e entorno do rio São Francisco. A disponibilidade de água, ainda que com graves oscilações, viabilizou a irrigação de lavouras e, nas áreas mais tecnificadas a frequência do pastoreio é, comparativamente, mínima. Em menor escala, as beiras de rios e riachos intermitentes, em especial os terraços mais espessos e orgânicos, são ocupados por cultivos de sequeiro ou irrigados que utilizam captação em poços artesianos. 
Há que se considerar que na classe Agricultura também se insere a agricultura de sequeiro, cuja importância para os pequenos produtores rurais é vital, visto garantir a alimentação da família e também dos animais. Cultivos de feijão, milho, mandioca, palma, dentre outros produtos de subsistência tem levado ao aumento gradativo da densidade das atividades rurais, ampliando a extensão das terras ocupadas e gerado maior pressão sobre os recursos ambientais. Tais cultivos compartilham, sazonalmente, os mesmos espaços destinados às pastagens e após a colheita e/ou períodos secos, cedem lugar para o gado, tipo de manejo rural praticado largamente no semiárido como forma de convivência com as secas e maximização da produção e do uso das terras. No entanto, a flutuabilidade das condições climáticas coloca a zona rural em condições de pobreza e insegurança alimentar, podendo forçar migrações para as cidades, quando ocorrem situações mais agudas.

\section{A Caatinga arbóreo-arbustiva antropizada, a Caatinga parque antropizada, e a Agricultura} recobrem, juntas, $56,70 \%$ da área total da região e têm provocado danos e degradação dos solos e da caatinga, onde um conjunto de processos físicos e biológicos está conduzindo para máxima degradação que repercute, de modo incisivo, sobre a perda de resiliência ou da capacidade de suporte das paisagens. A tendência para a elaboração de superfícies expostas irreversíveis, degradadas e desertificadas, fortemente desprovidas de cobertura vegetal, é evidente. São observadas incontáveis manchas ou células de solos pisoteados e totalmente desnudos, mineralizados e ressecados, ora quartzarênicos, ora litólicos. A exaustão dos recursos cede lugar para estes tipos de superfícies, frequentemente acompanhada de erosão, que ocorre em $16,31 \%$ da região - sulcos, ravinas, e múltiplas formas difusas menores ocorrem em toda parte, sobretudo nas áreas de ocupação antiga e com maior frequência das atividades rurais.

O Solo exposto, indicador de desertificação, é observado de forma pulverizada em toda a região, independentemente do tipo de solo. Suas características espectrais indicam ausência ou mínima cobertura vegetal mesclada ou interdigitada com diferentes superfícies rochosas, tais como, lajedos ${ }^{4}$, pavimentos detríticos pedregosos, baixos inselbergues, e areias. Sua origem está relacionada tanto a fatores naturais quanto antrópicos e, em grande parte, tratase da soma destes dois fatores.

\footnotetext{
${ }^{4} \mathrm{~A}$ maior exposição dos lajedos é referida no discurso oral dos sertanejos como o fenômeno das "pedras que crescem", numa alusão aos efeitos da erosão areolar junto aos lajedos.
} 
Admite-se também que as feições erosivas associadas aos solos expostos se encontrem disseminadas em superfícies muito mais amplas do que foi alcançado pelo mapeamento. A natureza da erosão em domínios semiáridos, mais sutis do que as incidentes em regimes subúmidos e úmidos, torna sua percepção pouco evidente. Porém, indicadores de erosão difusa, laminar, em lençol, sulcos e ravinas, foram observados em incontáveis situações de campo, como exposição de troncos e raízes; pequenos e efêmeros depósitos de sedimentos e de detritos orgânicos; e progressiva exposição de lajedos. Sulcos e canais de escoamento concentrado também testemunham a ação da erosão neste nível de processos. Os sedimentos erodidos são remanejados para níveis topográficos mais baixos até alcançar linhas de drenagem, onde formam amplos e, por vezes, espessos depósitos aluvionares. Apenas durante chuvas muito torrenciais são deslocados, porém sempre restarão volumes muito grandes preenchendo canais, riachos e rios.

A classe Aluvião constitui evidência contundente da importância dos processos erosivos mencionados. Apesar de terem sido mapeados menos de $1 \%$ de superfícies, esta classe é muito significativa diante das análises e inferências que têm sido colocadas até aqui. Foram observadas em campo ao longo de todas as linhas de escoamento, inclusive de sulcos efêmeros, remanejando sedimentos para baixadas, planícies e leitos fluviais, onde se estabilizam até novo episódio chuvoso.

O escoamento difuso, laminar e em lençol, constituem os processos iniciais de mobilização dos sedimentos, que adquirem competência erosiva e capacidade de transporte notável, quando ocorrem chuvas torrenciais. Os aguaceiros não se apresentam com a mesma violência em todos os períodos chuvosos, mas tipificam processos plúvio-fluviais de alta magnitude na região. Sua recorrência demonstra a essência da dinâmica geomorfológica semiárida, cuja contínua repetição constrói vastos depósitos aluvionares, inclusive terraços ao longo das baixadas e linhas de drenagem, expressando a energia da morfogênese frente aos fatores climáticos e biológicos deste domínio.

Os remanescentes de vegetação são pouco representativos na região, apenas $24,74 \%$ de fragmentos, associados geralmente a relevos de menor acessibilidade ou em unidades legalmente protegidas. 12,70\% correspondem à Caatinga arbórea arbustiva; 9,21\% à Caatinga arbórea arbustiva densa; e 0,86\% à Caatinga arbórea arbustiva aberta. A Caatinga Parque está 
restrita a apenas $1,72 \%$ da região; sobre afloramentos rochosos, inselbergues e serrotes, foi possível mapear 0,25\% de Caatinga arbórea arbustiva.

A Caatinga arbórea arbustiva e a Caatinga arbórea arbustiva densa foram discriminadas em função da densidade da vegetação e continuidade espacial da cobertura; as diferenças entre uma classe e outra são sutis. A âncora utilizada para dirimir dúvidas na vetorização destes polígonos na imagem de satélite foi textura e cor dos alvos. As caatingas mais ou menos densas foram deste modo, identificadas e separadas. Sobre o Tabuleiro de Tucano Norte encontram-se as maiores densidades, cuja preservação se deve não apenas às dificuldades de acesso, mas, sobretudo à presença das terras indígenas e da Estação Ecológica do Raso da Catarina - cerca de metade desta UC está localizada dentro da RPGA-MC. Ladeada por outras duas unidades estaduais, tais áreas protegidas formam um conjunto de grande valor ambiental e que têm conservado remanescentes importantes de caatingas. Orientada pelos mesmos critérios, a Caatinga arbórea arbustiva aberta, correspondeu às superfícies onde a caatinga apresenta menor densidade de cobertura e maior espaçamento entre as plantas. Em consequência há maior exposição à luz solar, aumentando a refletância do solo. É possível atribuir tais características tanto à fitofisionomia natural da caatinga arbórea arbustiva, bem como, às atividades humanas.

Os remanescentes de Caatinga Parque são muito exíguos, somente 1,72\%. Sua área de ocorrência foi delimitada pela presença do capim panasco que reflete uma textura lisa e esbranquiçada na imagem de satélite. Este estrato gramíneo forma uma densa cobertura sépia, no período seco, típico da caatinga parque.

A Caatinga arbórea arbustiva sobre afloramentos é avaliada, assim como as demais, como importante remanescente biológico, apesar da sua exígua abrangência areal, 0,25\%. Destacase, que tal como a classe Aluviões, estas coberturas sejam mais extensas, em razão da dificuldade de visualizá-las nesta escala de mapeamento. Os levantamentos de campo atestaram serrotes, inselbergues e lajedos de pequenas dimensões recobertos por caatinga, muitas vezes, densa.

Todos estes remanescentes revelam que, em que pese à relevância e a extensão das terras agro-ocupadas, a região ainda tem importante porção de seu território recoberta por vegetação. As maiores extensões ocorrem em Rodelas, onde 60,98\% do município mantém a 
vegetação natural. Constituem grandes remanescentes contínuos, com baixa fragmentação e grande interesse biológico, que integram áreas decretadas Corredor Ecológico, pelo MMA em 2007. As demais classes mapeadas são, comparativamente, de menor importância e revela que é crescente a ampliação de paisagens transformadas, um dos fatores que demonstram o quanto as atividades humanas têm impactado a região de forma negativa e gerado degradação e desertificação.

Os processos de desertificação (Figuras 3 e 4) foram observados nos levantamentos de campo, sobretudo nos municípios de Macururé e Juazeiro.

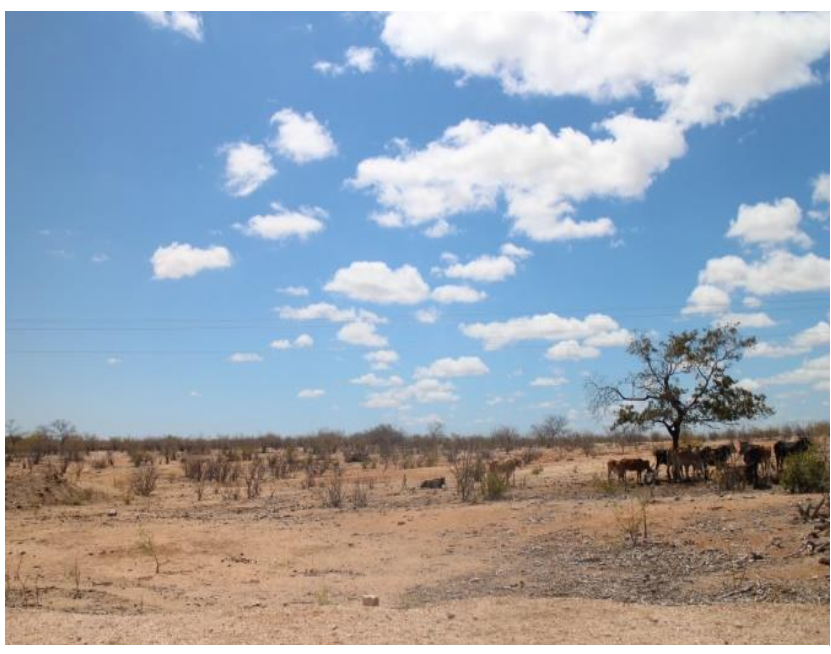

Figura 3. Células de desertificação, Macururé. Foto: Raquel Vale. 2017

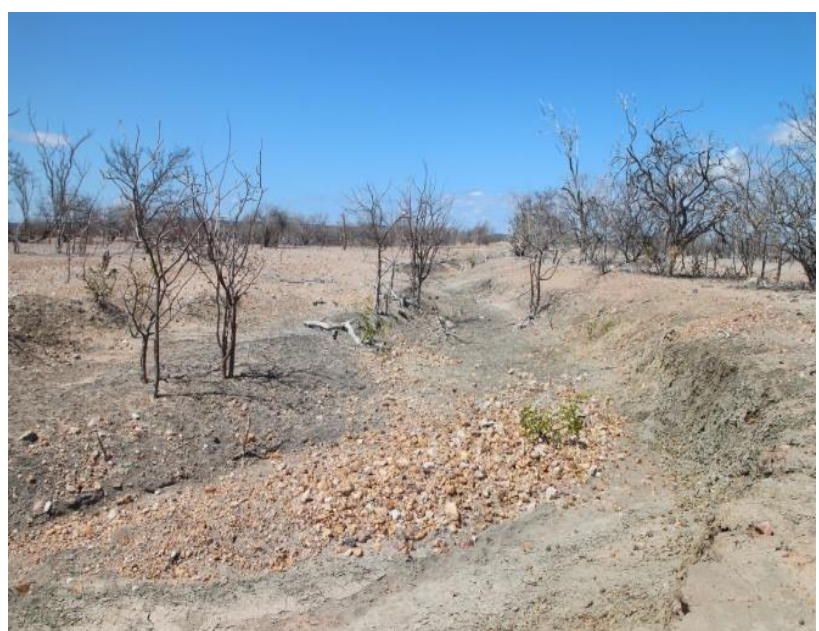

Figura 4. Células de desertificação, Juazeiro. Foto: Raquel Vale. 2017

Contudo, ocorrem de forma difusa em toda RPGA-MC e ocupam extensões que variam de centenas de quilômetros quadrados (células), até milhares de quilômetros quadrados (núcleos). Guardam características semelhantes entre si, o que sustenta a hipótese de uma gênese comum a todos:

- Vegetação muito rarefeita e acentuadamente fragmentada e degradada,

- Vegetação atipicamente homogênea,

- Grande exposição dos solos à radiação solar e intempéries,

- Grande exposição de raízes e lajedos, 
- Grande remoção de solos, sedimentos e matéria orgânica por erosão hídrica,

- Predomínio da pecuária extensiva, sobretudo de caprinos e ovinos.

Este conjunto de características evidencia que o predomínio das atividades primárias e a ocupação acentuada das terras rurais estão produzindo transformações nas paisagens bastante significativas - 75,26\% das terras da RPGA-MC estão afetadas por atividades humanas (Gráfico 1). Este dado demonstra o nível de maximização dos usos dos recursos ambientais, cujos danos deflagram processos de degradação aguda e sistêmica desertificação - que atingem diretamente a vegetação e, por conseguinte os recursos hídricos, os solos e as populações. Constituem uma teia de fatores e processos de alta complexidade, cujas repercussões temporais e espaciais encontram-se refletidas nas paisagens.

\section{Considerações finais}

Os dados derivados do mapa das Superfícies Transformadas e Remanescentes de Vegetação permitem atribuir à pecuária parte significativa na indução dos processos de desertificação em curso na RPGA-MC. Os danos advindos para os sistemas biológicos, edáficos e hídricos foram evidenciados por aquelas classes que associaram, à vegetação, antropização, fragmentação e declínio na densidade. O número elevado de classes mapeadas corrobora com esta premissa. Em contrapartida ao avanço destas áreas, que abragem mais de $75 \%$ da região, ocorrem remanescentes menores e descontínuos, que podem estar sob condições de pressão ambiental. Presume-se que os processos de desertificação estejam se desenvolvendo nestas áreas, sobretudo, nas mais expostas e sujeitas à erosão hídrica, resultando na mineralização dos solos e esgotamento das zonas de recarga. Pondera-se sobre a fragilidade ambiental das caatingas diante das pressões exercidas pelas atividades rurais, sobretudo, a pecuária extensiva. A correlação entre o uso das terras, a extensão das caatingas antropizadas e os solos desnudos, resguardando-se os de gênese natural, encontra-se no cerne desta questão. $A$ análise dos dados ratifica também que a fragilidade do bioma caatinga ao processo de desertificação é, de fato, importante. Sua regeneração é lenta, pois depende das chuvas, das formas de dispersão das sementes, da existência de um banco de sementes sadias no solo e da rebrota de tocos e raízes. Portanto, diante da magnitude dos usos que lhe são imputados, 
a capacidade de suporte ambiental das caatingas está sendo ultrapassada e dando origem a superfícies degradadas, expostas e em desertificação.

\section{Referências}

ARAÚJO FILHO, J.A. e CRISPIM, S.M.A. Pastoreio combinado de bovinos, caprinos e ovinos em áreas de caatinga no Nordeste do Brasil. In: Conferência virtual global sobre produção orgânica de bovinos de corte. Concórdia, SC. Anais... 2002. Corumbá, MS: Embrapa Pantanal, p.1-7.

BAHIA. Plano estadual de combate à desertificação e mitigação dos efeitos da seca. Salvador: SEMA, 2014.

BERNARDES, Nilo. As caatingas. Revista Estudos Avançados. 1999, vol. 13, no 36 . São Paulo. http://dx.doi.org/10.1590/S0103-40141999000200004

BERNARDES, Carmo. O gado e as larguezas dos Gerais. Revista Estudos Avançados. 1995, vol. 9, no 23. São Paulo. http://www.revistas.usp.br/eav/article/view/8846

BRASIL. Ministério do Meio Ambiente/MMA. Biodiversidade da Caatinga: áreas e ações prioritárias para a conservação. Organizadores: José Maria Cardoso da Silva, Marcelo Tabarelli, Mônica Tavares da Fonseca, Lívia Vanucci Lins. UFPE, Fundação de Apoio ao Desenvolvimento da UFPE, Conservation International do Brasil, Fundação Biodiversitas, EMBRAPA Semi-Árido. Brasília, DF. 2003.

BRASIL. Instituto Brasileiro de Geografia e Estatística - IBGE. https://ibge.gov.br/

BRASIL. Instituto Brasileiro de Geografia e Estatística - IBGE. Manual Técnico em Geociências: Manual Técnico da Vegetação Brasileira. 2a ed. Rio de Janeiro. 2012. Manual Técnico em Geociências: Manual Técnico de Uso da Terra. 2ª ed. Rio de Janeiro. 2006.

BRASIL. Ministério da Ciência, Tecnologia e Inovação (MCTI), Instituto Nacional do Semiárido (INSA). http://www.insa.gov.br/

BRASIL. Portaria no 131, de 28 de abril de 2006. Cria o Corredor Ecológico da Caatinga. 2006.

BRASIL. Nova delimitação do semiárido brasileiro. Ministério da Integração Nacional. Brasília. 2017.

BRASIL. Ministério do Meio Ambiente/MMA. Programa de Ação Nacional de Combate à Desertificação e Mitigação dos Efeitos da Seca, PAN-BRASIL. Edição Comemorativa dos 10 anos da Convenção das Nações unidades de Combate à Desertificação e Mitigação dos Efeitos da Seca - CCD. Brasília: MMA, 225p. 2004.

BRASIL. LEI № 9.433, de 8 de janeiro de 1997. Institui a Política Nacional de Recursos Hídricos, cria o Sistema Nacional de Gerenciamento de Recursos Hídricos, regulamenta o inciso XIX do art. 21 da Constituição Federal, e altera o art. 1으 da Lei no 8.001, de 13 de março de 1990, que modificou a Lei № 7.990, de 28 de dezembro de 1989.

CAVALCANTI, I. F. A., MARENGO, J. A., SATYAMURTY, P., NOBRE, C. A., TROSNIKOV, I., BONATTI, J. P., MANZI, A. O., TARASOVA, T., PEZZI, L. P., D’ALMEIDA, C., SAMPAIO, G., CASTRO, C., SANCHES, M. B., e CAMARGO, H.. Global climatological features in a simulation using the CPTEC-COLA AGCM, Journal of Climate. 2002, vol.15 no 21, p. 2965-2988.

COSTA NETO, E. M.; VALE, R.M.C.; FRANCA-ROCHA, W.J.S. Estudo multidisciplinar sobre processos de desertificação, estratégias adaptativas e empoderamento das comunidades que habitam nos sertões do estado da Bahia. In SIEDENBERG, Dieter R.; LOCK, Fernando Nascimento; LONDERO, Josirene Candido. Desenvolvimento regional: discussões e reflexões. Pelotas/RS: Editora Gráfica Universitária PREC-UFPEL. 2011, vol. 1, p. 191-202.

CONTI, J. B. A questão climática do nordeste brasileiro e os processos de desertificação. Revista Brasileira de Climatologia. 2005, Vol. 1, no 1. P.7-14.

FERREIRA, A. G. e MELLO, N. G. S. Principais sistemas atmosféricos atuantes sobre a região nordeste do Brasil e a influência dos oceanos pacífico e atlântico no clima da região. Revista Brasileira de Climatologia. 2005, vol. 1, no 1. 
GEIST, H. J. e LAMBIN, E. F. Dynamic causal patterns of desertification. Bioscience. 2004, vol. 54, no 9, p. 817829.

GIRÃO, Osvaldo S. Reconstrução do clima no nordeste brasileiro: secas e enchentes do século XIX. Finisterra. 2012, vol. XLVII, no 93, p. 29-47.

JATOBÁ, L.; SILVA, A. F e GALVÍNCIO, J. D. A dinâmica climática do semiárido em Petrolina-PE. Revista Brasileira de Geografia Física. 2017, vol. 10, no 01, p. 136-149.

LOBÃO, J. S. B. e VALE, R. M. C. Lógica fuzzy na modelagem da desertificação no estado da Bahia. Geografia, Rio Claro. 2013, vol. 38, no 1, p. 123-140.

NOBRE, P., MARENGO, J. A., CAVALCANTI, I. F. A., OBREGON, G., BARROS, V., CAMILLONI, I., CAMPOS, N. e FERREIRA, A. G. Seasonal-to-decadal predictability and prediction of South American climate. Journal of Climate. 2006, vol.19, p.5988-6004.

OYAMA, M. D. e NOBRE, C. A. A new climate vegetation equilibrium state for Tropical South America. Geophysical Research Letters. 2003, vol. 30, no 23, p. 2199. https://doi.org/10.1029/2003GL018600

PEREZ-MARIN, A. M., CAVALCANTE, A. M. B., MEdeIROS, S. S., TINÔCO, L. B. M. e SALCEDO, I. H. Núcleos de desertificação no semiárido brasileiro: ocorrência natural ou antrópica? Parcerias Estratégicas. 2012, BrasíliaDF, vol. 17, no 34, p. 87-106.

RÊGO. A. H. Os sertões e os desertos: o combate à desertificação e a política externa brasileira. Ministério das Relações Exteriores e Fundação Alexandre de Gusmão. Brasília. 204 p. 2012.

REPOSSI, P. V. e CANZIANI, P. O. Detección y estudio de las perturbaciones generadas en la atmósfera por los eventos “El Niño Benguela". Revista de Climatología, 2009, Buenos Aires, Argentina, vol. 9, p. 15-23.

SAMPAIO, E. V. S. B; ARAÚJO, M. S. B. e SAMPAIO, Y. S.B. Propensão à desertificação no semi-árido brasileiro. Revista de Geografia (Recife), 2008, vol. 22, no 2, p. 59-76.

SAMPAIO, E.V.S.B.; SAMPAIO, Y.; VITAL, T.; ARAÚJO, S.B. e SAMPAIO, G.R. Desertificação no Brasil: conceitos, núcleos e tecnologias de recuperação. Recife: Editora Universitária UFPE. 2003.

VALE, Raquel M. C. Das paisagens frágeis às terras excluídas dos sertões secos: a desertificação no sub-médio São Francisco, Bahia-Brasil. 2018. Espanha: Faculdade de História, Geografia e História da Arte, 2018. 340p (Tese, doutorado em Análise e Gestão do Território e da Paisagem. Defesa: 30/11/2018. Santiago de Compostela). 